ARTICLE

\title{
Zinc ion thermal charging cell for low-grade heat conversion and energy storage
}

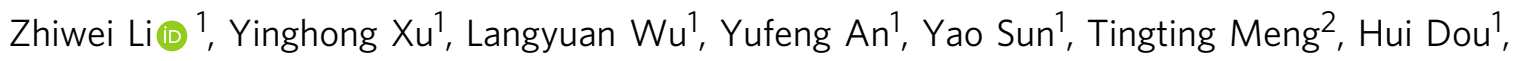
Yimin Xuan (1) ${ }^{2 \otimes} \&$ Xiaogang Zhang (i) ${ }^{1 凶}$

Converting low-grade heat from environment into electricity shows great sustainability for mitigating the energy crisis and adjusting energy configurations. However, thermally rechargeable devices typically suffer from poor conversion efficiency when a semiconductor is employed. Breaking the convention of thermoelectric systems, we propose and demonstrate a new zinc ion thermal charging cell to generate electricity from low-grade heat via the

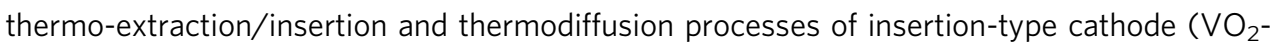
$\mathrm{PC}$ ) and stripping/plating behaviour of $\mathrm{Zn}$ anode. Based on this strategy, an impressively high thermopower of $\sim 12.5 \mathrm{mV} \mathrm{K}^{-1}$ and an excellent output power of $1.2 \mathrm{~mW}$ can be obtained. In addition, a high heat-to-current conversion efficiency of 0.95\% (7.25\% of Carnot efficiency) is achieved with a temperature difference of $45 \mathrm{~K}$. This work, which demonstrates extraordinary energy conversion efficiency and adequate energy storage, will pave the way towards the construction of thermoelectric setups with attractive properties for high valueadded utilization of low-grade heat.

\footnotetext{
${ }^{1}$ Jiangsu Key Laboratory of Electrochemical Energy Storage Technologies, College of Material Science and Engineering, Nanjing University of Aeronautics and Astronautics, 211106 Nanjing, China. ${ }^{2}$ School of Energy and Power Engineering, Nanjing University of Aeronautics and Astronautics, 210016 Nanjing, P. R.

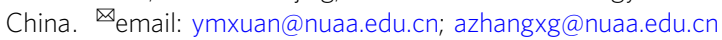


$\mathrm{T}$ he high value-added utilization of plentiful and sustainable heat power has spurred urgent development of costeffective and safe technologies for harvesting low-grade heat $\left(<100^{\circ} \mathrm{C}\right)$ into electricity ${ }^{1-3}$. Among various advanced systems, electronic thermoelectric devices (e-TEs) using narrowbandgap semiconductors can realize the conversion of low-grade heat to meet the needs of the electronic market (i.e., low-cost, safety, high efficiency) based on the Seebeck effect. For a typical e-TE material, the Seebeck coefficient $(\alpha)$ is only $\sim 100 \mu \mathrm{V} \mathrm{K}^{-14}$. As a result, it is very challenging to generate a sufficient voltage from 1 to $5 \mathrm{~V}$ by the integration of numerous e-TEs. Therefore, a new type thermal charging cell with enhanced performance has to be further designed and considered.

Recently, an alternative approach, namely, ionic thermoelectric devices (i-TEs), was adopted for direct energy harvesting, which delivers two different mechanisms including thermogalvanic effect and thermodiffusion effect ${ }^{2,5}$. Low-grade heat can be continuously converted into electricity because a temperature difference can induce a voltage difference. For instance, a thermally chargeable supercapacitor was demonstrated by Zhang and coworkers based on the thermodiffusion effect. An $\alpha$ value of $1.21 \mathrm{mV} \mathrm{K}^{-1}$ could be obtained at a temperature difference of $52 \mathrm{~K}$ with $1.0 \mathrm{~mol} \mathrm{~L}^{-1} \mathrm{KNO}_{3}$ electrolyte and a porous carbon (PC) electrode ${ }^{6}$. However, the heat-to-current performance in this thermally chargeable supercapacitor is still limited by the adsorption/desorption and diffusion of electrolyte ions. An alternative strategy is to design an electrolyte by introducing redox couples such as ferro/ferricyanide $\left[\mathrm{Fe}(\mathrm{CN})_{6}{ }^{4-}-1\right.$ $\left.\mathrm{Fe}(\mathrm{CN})_{6}{ }^{3-}\right]^{2,5,7-10}$. Liu et al. has reported ionic thermoelectric materials using $\mathrm{KCl}$ and $\left[\mathrm{Fe}(\mathrm{CN})_{6}^{4-} / \mathrm{Fe}(\mathrm{CN})_{6}{ }^{3-}\right]$ for the synergistic effect of thermogalvanic and thermodiffusion ${ }^{2}$. Consequently, a superior $\alpha$ value of $17.0 \mathrm{mV} \mathrm{K}^{-1}$ was achieved using body heat and an output voltage of over $2 \mathrm{~V}$ was generated by integrating 25 unipolar units. Among various thermal systems, liquid-state thermocells show great advantages in terms of their cost-effectiveness and scalability for low-grade heat conversion. Although considerable effort has been devoted to realizing a highly efficient conversion of low-grade heat, the output voltage is greatly limited by the electrode/electrolyte interface and energy storage mechanism. In addition, the low Carnot-relative efficiency $(<5 \%)$ has been challenging to improve even under ideal laboratory conditions. It is reasonable to propose that the construction of a hybrid device based on the Soret effect may exhibit high potential in the harvesting of electricity with a steady temperature gradient.

Aqueous zinc ion batteries (ZIBs) have emerged as one of promising candidates for energy storage due to the merits of $\mathrm{Zn}$ anodes, such as cost-effectiveness, multivalent feature, and satisfactory stability ${ }^{11-14}$. When introducing the concept of ZIBs into heat-to-electricity conversion, various mechanisms can be proposed through the synergistic effect among the thermogalvanic effect of $\mathrm{Zn}$ anodes and the thermodiffusion and thermoextraction of ions in electrolytes and cathodes, respectively (Fig. 1). The Zn-based thermally chargeable supercapacitors using capacitive cathodes (i.e., PC) can generate electricity based on the thermodiffusion effect of electrolyte ions along with the stripping and plating of $\mathrm{Zn}$ anode. Typically, the applied temperature gradients can cause both cations and anions to migrate from the hot side to the cold side (Fig. 1a). A thermodiffusive voltage can be generated and defined as $\Delta V_{\mathrm{td}}=-\left(\hat{\mathrm{u}}_{\mathrm{H}}-\hat{\mathrm{u}}_{\mathrm{C}}\right) / e$. In general, the intercalated $\mathrm{Zn}^{2+}$ migrates to the surface of $\mathrm{Zn}$ anode and spontaneously experiences a plating process. Based on the extraction of ions inserted in the selected cathode (VO), the transferred charges to the hot side reasonably improve the obtained electrochemical potential (Fig. 1b). However, the relatively sluggish kinetics of pure battery-like systems greatly impede their practical applications. Therefore, the $\mathrm{Zn}$-based thermal charging cells (ZTCCs), which combine the thermodiffusion of ions on PC and the extraction of ions from an insertion-type VO electrode, can output a higher voltage (Fig. 1c). Notably, vanadium-based oxides demonstrate promising performances owing to their multiple valence feature and unique crystal structure for ion storage ${ }^{11,13,15}$. However, the sluggish kinetics, poor conductivity, and structural deterioration involved in the insertion/extraction of $\mathrm{Zn}^{2+}$ always hinder their large-scale applications, that is, the rational design of satisfying vanadiumbased oxides for energy storage and conversion is still in its infancy.

Herein, we propose and develop promising ZTCCs by combining $\mathrm{Zn}$ anode and $\mathrm{VO}_{2}-\mathrm{PC}$ cathode. As a result, the $\mathrm{VO}_{2}-\mathrm{PC}$ based ZTCC can generate electricity from low-grade heat through the synergistic effect between thermodiffusion and thermoextraction. Remarkably, a high Seebeck coefficient of $12.5 \mathrm{mV} \mathrm{K}^{-1}$ and conversion efficiency of $0.95 \%$ (7.25\% of Carnot-relative efficiency) can be attained with a temperature gradient of $45 \mathrm{~K}$. Moreover, $\mathrm{VO}_{2}-\mathrm{PC}$ shows promising capacity, good rate capability, and excellent durability for energy storage. In addition, the proof-of-concept set-up displays satisfying application potential for harvesting energy from waste heat due to its ultrahigh output voltage of $\sim 1 \mathrm{~V}$ with only one unit.

\section{Results}

Preparation and characterization of $\mathrm{VO}_{2}-\mathrm{PC}$ nanosphere. The spherical vanadium-polydopamine (V-PDA) composites were rationally synthesized by a solution-based strategy using dopamine and ammonium metavanadate as carbon source and vanadium source, respectively. After pyrolysis under argon atmosphere, the PDA and V-based species were evolved into hierarchical PC matrix and anchored vanadium dioxide $\left(\mathrm{VO}_{2}\right)$ along with gas escape, and the details can be seen in the "Methods" section. Field-emission scanning electron microscope (SEM) and transmission electron microscope (TEM) were employed to observe the microstructures of as-prepared materials. It can be found that the morphology of pure PDA-derived PC is uneven nanospheres with different diameters ranging from $100 \mathrm{~nm}$ to $\sim 1 \mu \mathrm{m}$ (Supplementary Fig. 1a, b). In particular, the $\mathrm{VO}_{2}-\mathrm{PC}$ is engineered by uniform nanospheres with a size of about $250 \mathrm{~nm}$ (Supplementary Fig. 2a, b). Significantly, the $\mathrm{VO}_{2}$ is uniformly distributed in the $\mathrm{VO}_{2}$ - $\mathrm{PC}$ sample with a high content of $65.4 \mathrm{wt} \%$ determined by the thermogravimetric analyses (Supplementary Fig. 3). Through the obvious spherical morphology (Supplementary Fig. 2c), it is can be noted that the porous $\mathrm{VO}_{2}-\mathrm{PC}$ shows an amorphous feature. From the highresolution TEM image of $\mathrm{VO}_{2}-\mathrm{PC}$ (inset of Supplementary Fig. 2c), a lattice fringe with the spacing of $0.353 \mathrm{~nm}$ can be attributed to the (110) plane of monoclinic $\mathrm{VO}_{2}$. Such unique integration of $\mathrm{VO}_{2}$ and $\mathrm{PC}$ in the $\mathrm{VO}_{2}-\mathrm{PC}$ would be beneficial to provide abundant pathways and electroactive sites for $\mathrm{Zn}^{2+}$ diffusion and storage, which could enhance the rate capability and specific capacity of as-designed devices. The energy-dispersive Xray spectrometry elements mapping images in Supplementary Fig. $2 \mathrm{~d}$ further confirm the coexistence and extremely even distribution of $\mathrm{C}, \mathrm{N}, \mathrm{O}$, and $\mathrm{V}$ elements in the $\mathrm{VO}_{2}-\mathrm{PC}$ sphere. The $\mathrm{X}$-ray diffraction (XRD) pattern of $\mathrm{VO}_{2}-\mathrm{PC}$ is displayed in Supplementary Fig. 2e, in which almost all the peaks can be well indexed to the monoclinic $\mathrm{VO}_{2}(\mathrm{PDF} \# 81-2392)^{16}$. The crystal structure of layered $\mathrm{VO}_{2}$ is presented in the inset of Fig. 1e, and relatively large one-dimensional tunnels are formed by the shared corners of $\mathrm{V}_{4} \mathrm{O}_{10}$ in $\mathrm{VO}_{2}$, implying fast transport of electrolyte ions. Supplementary Fig. $2 \mathrm{f}$ shows the Raman spectrum of $\mathrm{VO}_{2}-$ PC. The characteristic Raman shifts can be assigned to the layered 
a

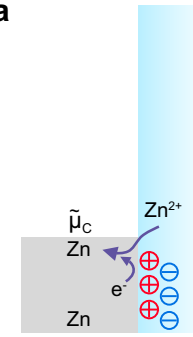

Cold side

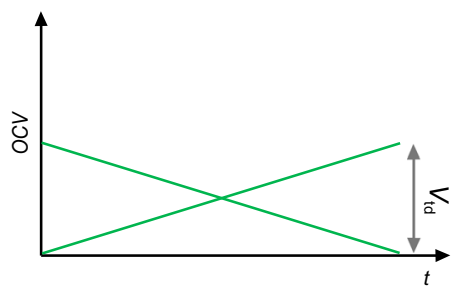

b
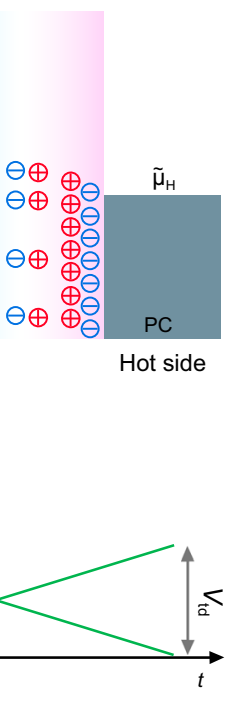
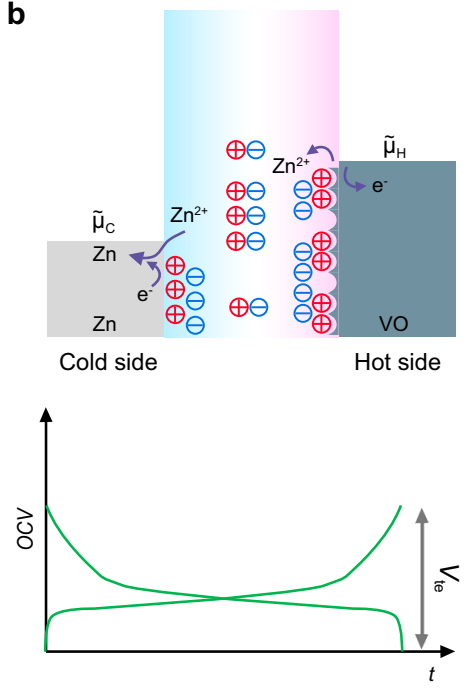

C
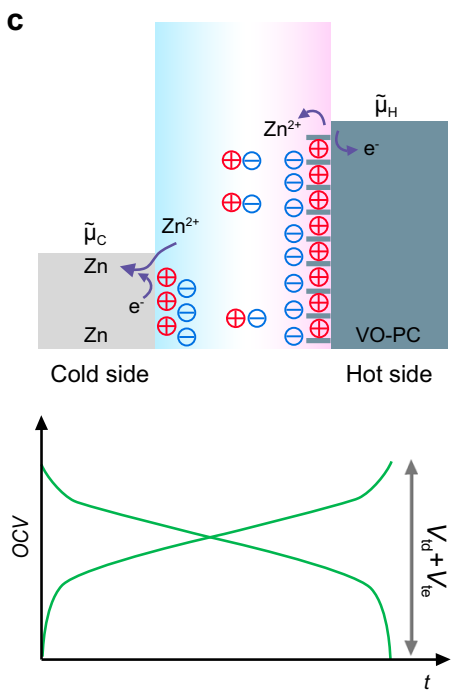

Fig. 1 Concept and working mechanism of Zn-based thermally chargeable systems. a PC-based thermodiffusion effect, $\mathbf{b}$ VO-based thermoextraction effect, and $\mathbf{c}$ VO-PC-based synergistic effect.

structure of $\mathrm{VO}_{2}$ crystalline $\left(140.2 \mathrm{~cm}^{-1}\right), \mathrm{V}=\mathrm{O}$ bending vibration (279.4 and $\left.406.7 \mathrm{~cm}^{-1}\right), \mathrm{V}-\mathrm{O}-\mathrm{V}$ stretching vibration $\left(686.9 \mathrm{~cm}^{-1}\right)$, and $\mathrm{V}=\mathrm{O}$ stretching vibration $\left(992.6 \mathrm{~cm}^{-1}\right)^{17}$. Besides, the valence of $\mathrm{V}$ element was investigated by the $\mathrm{X}$-ray photoelectron spectroscopy (XPS) spectrum in Supplementary Fig. $2 \mathrm{f}$. As analyzed, only $\mathrm{V}^{4+}$ exists in the obtained product, which suggests the successful preparation of standard $\mathrm{VO}_{2}{ }^{18}$. More importantly, when using molybdenum (Mo) and tungsten $(\mathrm{W})$ as the metal sources, this proposed strategy also can reasonably form the corresponding $\mathrm{Mo}_{4} \mathrm{O}_{8}-\mathrm{PC}$ and $\mathrm{W}_{3} \mathrm{O}_{9}-\mathrm{PC}$, as proved by the SEM images and XRD results (Supplementary Fig. 4).

Electrochemical performance of ZTCCs. To accurately evaluate the practical application of electrode materials in the conversion of low-grade heat, we have constructed a non-isothermal $\mathrm{H}$ cell with $\mathrm{Zn}-\mathrm{G}$ anode and $\mathrm{VO}_{2}-\mathrm{PC}$ cathode, as illustrated in Fig. 2a. During the measurements, the $\mathrm{VO}_{2}-\mathrm{PC}$ cathode pre-intercalated with $\mathrm{Zn}^{2+}$ is heated by hot water bath while the $\mathrm{Zn}-\mathrm{G}$ anode is unheated to form a temperature difference $(\Delta T)$. It should be noted that the $\Delta T$ between anode and cathode is detected by the thermocouple inserted in each chamber. To minimize the kinetics effects, an ultralow current of $40 \mu \mathrm{A}$ was applied to various electrodes without temperature gradient (Fig. 2b). Clearly, the $\mathrm{VO}_{2}-\mathrm{PC}$ combines the characteristics of its components including high porosity of $\mathrm{PC}$ and electrical activity of $\mathrm{VO}_{2}$, which endows $\mathrm{VO}_{2}$-PC electrode with a shorter time to achieve the open-circuit voltage than pure $\mathrm{VO}_{2}$ under this case. The fast increase of voltage at the initial state is mainly caused by the desorption of electrolyte ions. Meanwhile, the platforms around 0.6 and $0.9 \mathrm{~V}$ that appeared in both $\mathrm{VO}_{2}$ and $\mathrm{VO}_{2}-\mathrm{PC}$ are assigned to the extraction of ions. The evolution of the output voltage $(\Delta V)$ under various temperature differences for the $\mathrm{VO}_{2}-\mathrm{PC}$-, $\mathrm{VO}_{2}$ - and $\mathrm{PC}$ based ZTCCs are profiled in Fig. 2c. As we gradually increase the heat input, the temperature difference and output voltage can achieve a series of steady states within $2400 \mathrm{~s}$. Notably, the output voltage is dramatically increased with a $\Delta T$ of $5 \mathrm{~K}$ for PC-based ZTCC, which is mainly caused by the fast desorption of electrolyte ions. When the $\Delta T$ reaches $10 \mathrm{~K}$, a relatively stable voltage of $\sim 1.1 \mathrm{~V}$ can be obtained. Interestingly, the output voltage caused by the desorption of electrolyte ions in the initial state $(\Delta T=5 \mathrm{~K})$ is relatively weakened and only $\sim 0.5 \mathrm{~V}$ can be achieved for
$\mathrm{VO}_{2}$ - $\mathrm{PC}$, which is also higher than that of $\mathrm{VO}_{2}(\sim 0.4 \mathrm{~V})$. This significant difference between $\mathrm{PC}$ and $\mathrm{VO}_{2}-\mathrm{PC}$ may be highly determined by their different charge storage mechanisms. As discussed above, the inserted $\mathrm{Zn}^{2+}$ can react with the $\mathrm{VO}_{2}$ and achieve stable bonding in the form of chemical bonds ${ }^{19}$. Thus, great heat is required to release such combined $\mathrm{Zn}^{2+}$, which also implies a high energy input. Consequently, a comparable output voltage of $\sim 1.01 \mathrm{~V}$ can be delivered from the $\mathrm{VO}_{2}$-PC-based ZTCC under the temperature difference of $45 \mathrm{~K}$. However, only $\sim 0.87 \mathrm{~V}$ is achieved for $\mathrm{VO}_{2}$-based set-up due to the sluggish extraction of ions from the highly ordered crystals. Meanwhile, we have performed XRD patterns of electrodes after the thermal charging process from 5 to $45 \mathrm{~K}$, as shown in Supplementary Fig. 5. The (110) plane of $\mathrm{VO}_{2}$ shifts from $25.8^{\circ}$ to $\sim 25^{\circ}$ due to the $\mathrm{Zn}^{2+}$ insertion during the electrochemical discharging process (from the initial state to $5 \mathrm{~K}$-s). The $\mathrm{VO}_{2}-\mathrm{PC}$ cathode remains unchanged at the temperature difference of $5 \mathrm{~K}$ (from $5 \mathrm{~K}$-s to 5 $\mathrm{K}-\mathrm{e})$, but the peaks are changed and slightly shifted from $\sim 25^{\circ}$ to $25.3^{\circ}$ during 10 to $45 \mathrm{~K}$. This interesting phenomenon suggests that the rapid desorption of adsorbed ions on the $\mathrm{VO}_{2}-\mathrm{PC}$ does not change the electrode structure. However, the crystal structure of $\mathrm{VO}_{2}$ can be partially changed by gradual extraction of inserted ions under temperature gradient, which is mainly induced by the redox reaction between $\mathrm{Zn}_{x} \mathrm{VO}_{2}$ and $\mathrm{VO}_{2}$. These findings also are in line with the electrochemical results. Figure $2 \mathrm{~d}$ summarizes the detailed output voltage value at various temperature differences of as-constructed ZTCCs. Obviously, the increasing trend of $\Delta V$ is highly consistent with the kinetics of adsorption/desorption and insertion/extraction. According to the relationship between $\Delta V$ and $\Delta T$, the temperature/Seebeck coefficient $(\alpha)$ can be calculated, which is described by the following equation ${ }^{6,20}$ :

$$
\alpha=\frac{\partial V}{\partial T}
$$

As shown in Fig. 2e, an improved thermopower from 5.3 to $12.5 \mathrm{mV} \mathrm{K}^{-1}$ can be achieved by introducing $\mathrm{VO}_{2}$ into $\mathrm{PC}$ matrix using an aqueous electrolyte. Compared with the $\mathrm{PC}$ and pure $\mathrm{VO}_{2}$, the higher $\alpha$ value of $\mathrm{VO}_{2}-\mathrm{PC}$ is probably caused by the synergistic effect of thermodiffusion and thermoextraction. For convenience, the optimized crystal structures of $\mathrm{VO}_{2}, \mathrm{Zn}-\mathrm{VO}_{2}$, and $\mathrm{Zn} / \mathrm{H}_{2} \mathrm{O}-\mathrm{VO}_{2}$ are displayed in Fig. 2f. The possible electrochemical processes involved in both electrodes can be described as follows: 
a

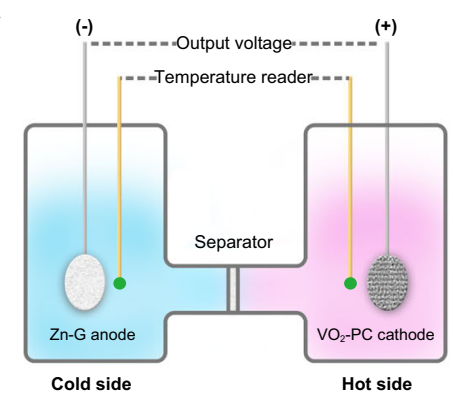

d
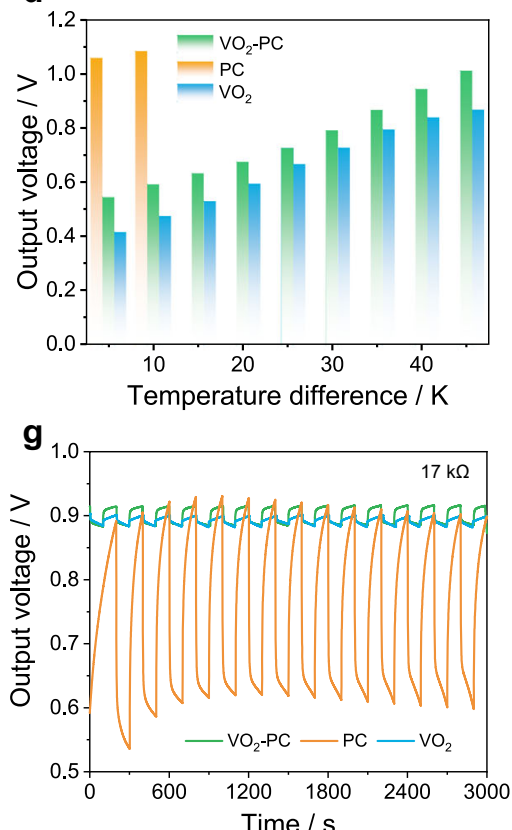

b

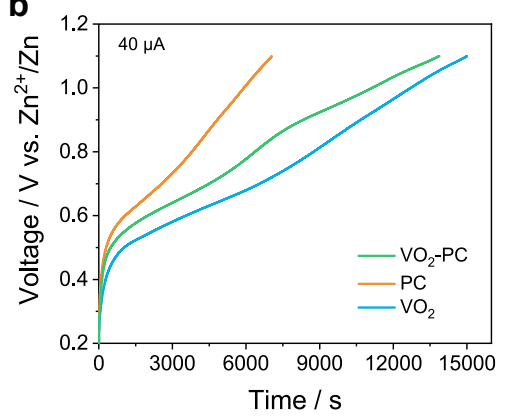

e

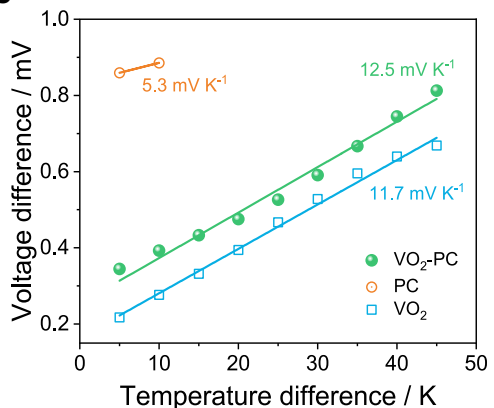

h

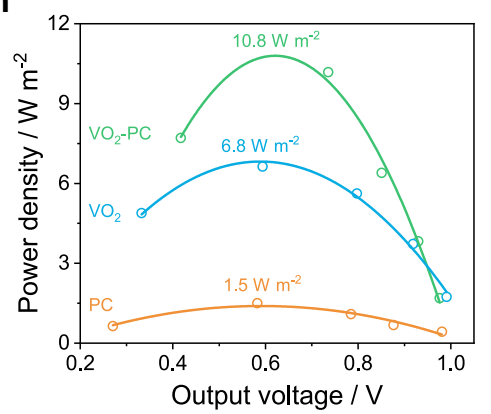

c

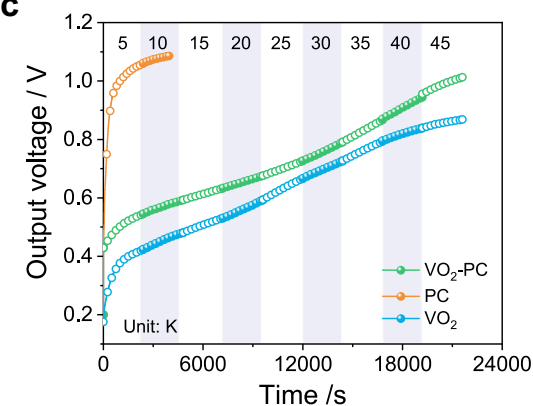

f

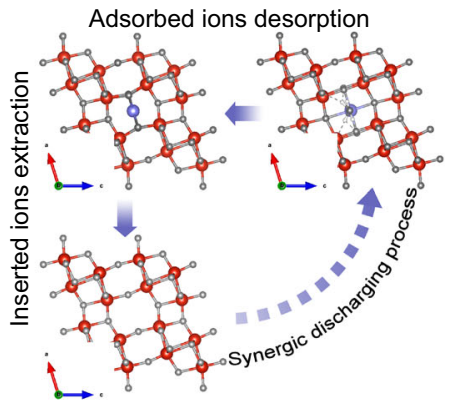

i

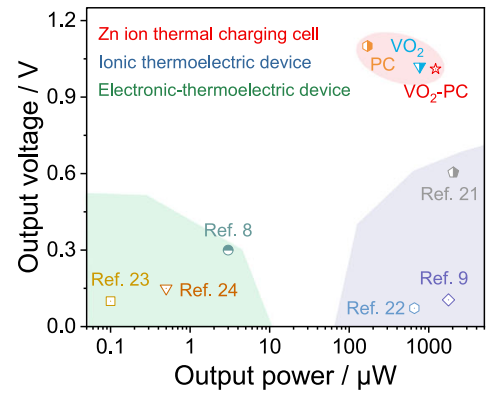

Fig. 2 Construction and performance of ZTCCs. a The schematic diagram of the non-isothermal cell. $\mathbf{b}$ Electrochemical charge curves with a current of $40 \mu \mathrm{A}$. c Evolution of the output voltage with various temperature gradients. $\mathbf{d}$ The output voltage at various temperature differences. e Voltage difference vs. temperature difference. $\mathbf{f}$ The corresponding structural changes of $\mathrm{VO}_{2}$ during energy conversion. $\mathbf{g}$ The discharging curves with a load of $17 \mathrm{k} \Omega$. $\mathbf{h}$ Plots of current densities and power densities under various output voltages. i Comparison in output power and voltage.

Cathode:

$$
\mathrm{VO}_{2}+x \mathrm{Zn}^{2+}+y \mathrm{H}_{2} \mathrm{O}+2 x \mathrm{e}^{-} \leftrightarrow \mathrm{Zn}_{x} \mathrm{VO}_{2} \cdot y \mathrm{H}_{2} \mathrm{O}
$$

Anode:

$$
x \mathrm{Zn} \leftrightarrow x \mathrm{Zn}^{2+}+2 x \mathrm{e}^{-}
$$

With the change of $\Delta T$, the reversible "breathing" of $\mathrm{VO}_{2}$ unit cell together with the insertion/extraction of electrolyte ions can realize the continuous conversion and utilization of low-grade heat. It is worth mentioning that the relative contribution to the total thermopower can be distinguished as follows: $3.6 \%$ of redox entropy of $\mathrm{Zn} / \mathrm{Zn}^{2+}, 30.1 \%$ of redox entropy of $\mathrm{Zn}_{x} \mathrm{VO}_{2} / \mathrm{VO}_{2}$, $7.6 \%$ contribution of thermodiffusion of $\mathrm{Zn}\left(\mathrm{CF}_{3} \mathrm{SO}_{3}\right)_{2}$ electrolyte, and $58.7 \%$ contribution of thermodiffusion of electrolyte ions in $\mathrm{VO}_{2}-\mathrm{PC}$ electrode (Supplementary Note 1 and Supplementary Fig. 6). Motivated by the high voltage of as-assembled ZTCCs, a fixed resistor $(17 \mathrm{k} \Omega$ ) was employed to study the corresponding rechargeable behavior. Significantly, the energy decay and thermocharging behavior of $\mathrm{VO}_{2}$-PC-based ZTCC is much comparable to that of $\mathrm{PC}$ - and $\mathrm{VO}_{2}$-based ZTCC even over $3000 \mathrm{~s}$ (15 cycles) with a stable voltage of $0.9 \mathrm{~V}$, demonstrating the satisfying performance of $\mathrm{VO}_{2}$-PC-based ZTCC in electronics (Fig. $2 \mathrm{~g}$ ). In addition, the relatively rapid chargeability of ZTCCs within $100 \mathrm{~s}$ can be highly determined by their low energy decay and fast charge response. Furthermore, a series of fixed resistors were used to investigate the power density $(P)$ according to $P=V^{2} / R$. More excitingly, an ultrahigh power density of $10.8 \mathrm{~W} \mathrm{~m}^{-2}$ can be fitted by $\mathrm{VO}_{2}$-PC-based ZTCC with a load resistor of 200-470 $\Omega$, which is much better than that of PC- and $\mathrm{VO}_{2}$-based ZTCCs (Fig. 2h). When comparing the output voltage and power of ZTCCs with other reported systems, as-built ZTCCs are more competitive than that of previously reported electronic-thermoelectric devices and ionic thermoelectric devices (Fig. 2i), demonstrating the availability of ZTCCs as promising devices for low-grade heat conversion $8,9,21-24$.

Conversion efficiency of ZTCCs. The rate behavior of the thermal charging cell was recorded by the galvanostatic discharge curves after charging with various temperature differences. As profiled in Supplementary Fig. 7a, the discharge time gradually increases from 240 to $3895 \mathrm{~s}$ with the input of temperature gradient from 5 to $45 \mathrm{~K}$, indicating the conversion capability of ZTCCs from heat to electricity. Moreover, we have carried out the discharge performances of devices after charging with heat process and hybrid process to distinguish the ratio of heat charge part (Supplementary Fig. 7b). The $\mathrm{VO}_{2}$-PC-based ZTCC can obtain a moderate voltage of $\sim 1.01 \mathrm{~V}$ after charging with a temperature difference of $45 \mathrm{~K}$. The output voltage can be greatly 
a

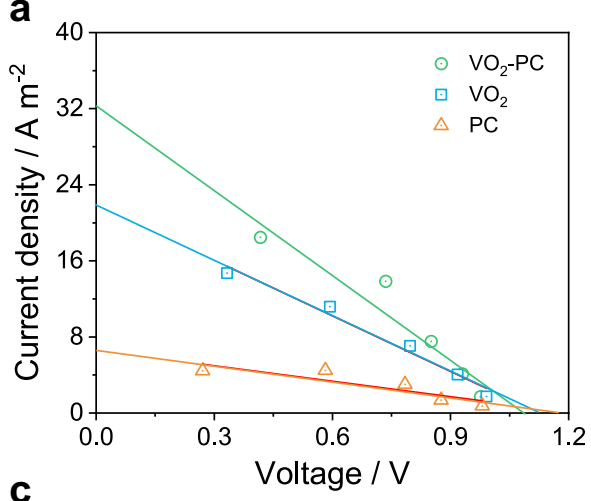

C

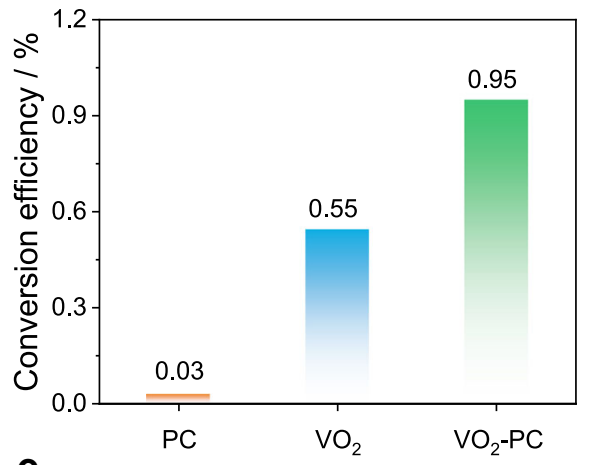

b

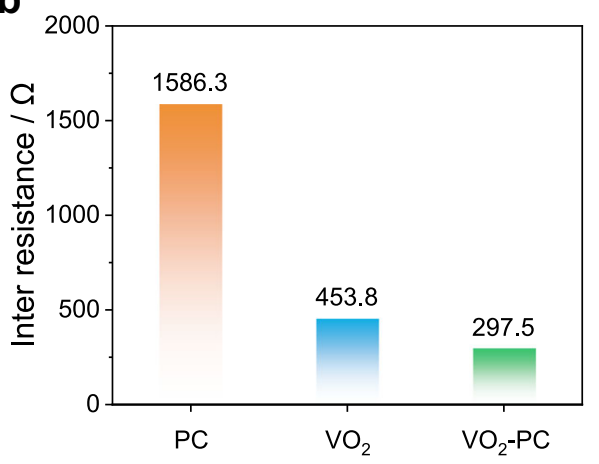

d

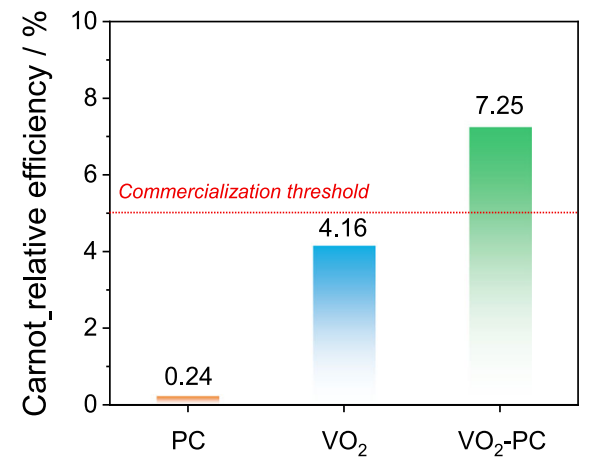

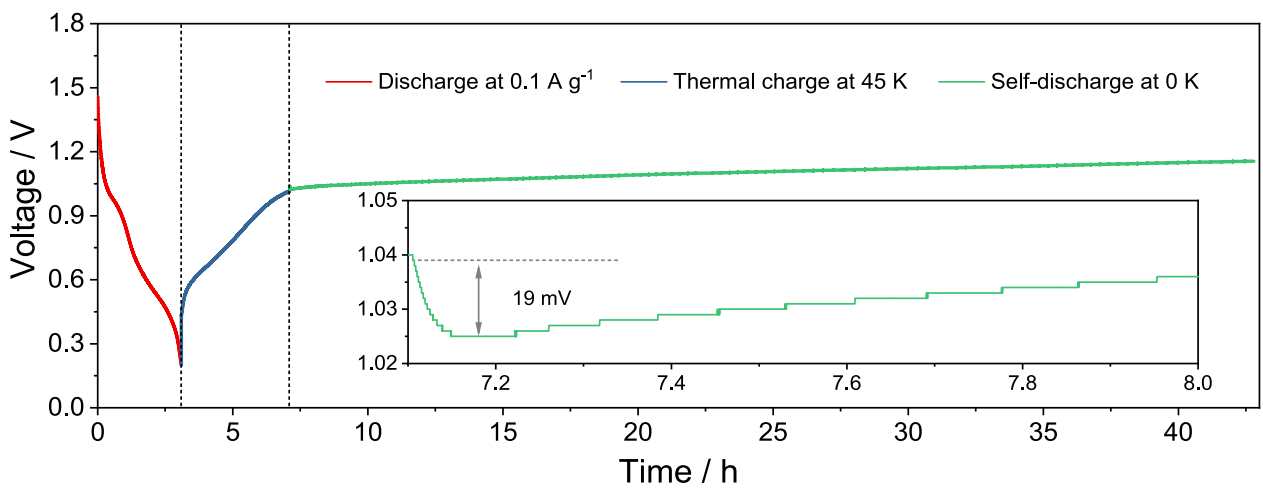

Fig. 3 Heat-to-electricity conversion of ZTCCs. a Current-voltage plot, $\mathbf{b}$ inter resistance, c conversion efficiency, and $\mathbf{d}$ Carnot-relative efficiency for PC, $\mathrm{VO}_{2}$, and $\mathrm{VO}_{2}-\mathrm{PC}$, respectively. e Self-discharging curve after eliminating the temperature gradient.

enhanced to $1.6 \mathrm{~V}$ by introducing the power charge process. According to the discharging curves, the capacity obtained by the thermal process accounts for $\sim 46.7 \%$ of the capacity obtained with the hybrid charging mode, suggesting great potential of asproposed ZTCC in practical applications. Moreover, the shortcircuit current and open-circuit voltage were recorded by the plot in Fig. $3 \mathrm{a}$ after charging under $45 \mathrm{~K}$ with various resistances. As profiled, the $\mathrm{VO}_{2}$-PC-based ZTCC exhibits a higher current response $\left(32.3 \mathrm{~A} \mathrm{~m}^{-2}\right)$ than that of $\mathrm{PC}\left(6.5 \mathrm{~A} \mathrm{~m}^{-2}\right)$ and $\mathrm{VO}_{2}$ (21.8 $\left.\mathrm{A} \mathrm{m}^{-2}\right)$, suggesting its lower inter resistance. Consequently, a relatively low resistance value of $297.5 \Omega$ can be obtained by the $\mathrm{VO}_{2}$-PC-based ZTCC, while the value is 1586.3 and $453.8 \Omega$ for $\mathrm{PC}$ and $\mathrm{VO}_{2}$, respectively. This satisfying result could be mainly caused by the synergistic effect by introducing carbon matrix into metallic species. Besides, the heat-to-current conversion efficiency $(\eta)$ of the ZTCC is estimated by Eq. (4), which can be expressed as $^{22}$ :

$$
\eta=\frac{\alpha^{2} \Delta T}{4 \kappa} \cdot \frac{d}{A R_{\text {Cell }}}
$$

where $\kappa$ is the thermal conductivity, $d$ is the inter-electrode spacing, $A$ is the cross-sectional area, and $R_{\text {Cell }}$ is the inter resistance of the ZTCCs. Based on the parameters summarized in Supplementary Table 1 and Supplementary Table 2, different energy conversion efficiency can be obtained, which still is a controversial point in thermoelectric. Details of efficiency calculation are shown in Supplementary Note 2. As plotted in Fig. 3c, the $\eta$ of ZTCC reaches $0.95 \%$ by the $\mathrm{VO}_{2}-\mathrm{PC}$-based ZTCC at $45 \mathrm{~K}$, which is significantly higher than that of $\mathrm{VO}_{2}$ and $\mathrm{PC}$-based ZTCCs. When considering the corresponded Carnot efficiency, the $\mathrm{VO}_{2}$-PC-based ZTCC can obtain the highest Carnot-relative efficiency $\left(\eta_{\mathrm{r}}\right)$ of $7.25 \%$ at a $\Delta T$ of $45 \mathrm{~K}$ owing to its high power density (Fig. $3 \mathrm{~d}$ ). In addition, the $\eta_{\mathrm{r}}$ for $\mathrm{VO}_{2}$-PC-based ZTCC substantially surpasses the predicted commercialization threshold and some previously reported value $22,25,26$. In addition, the selfdischarging curve is adopted to study the electrochemical behavior for ZTCC (Fig. 3e). After discharging at a current density of $0.1 \mathrm{~A} \mathrm{~g}^{-1}$ and thermal charge at a $\Delta T$ of $45 \mathrm{~K}$, an output voltage of $\sim 1.01 \mathrm{~V}$ can be rationally achieved. There is a negligible voltage drop $(19 \mathrm{mV})$ occurred when eliminating the temperature 
a

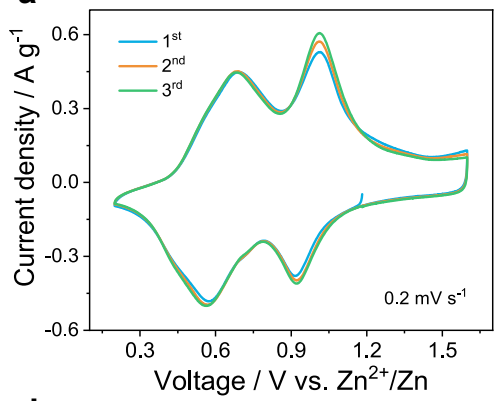

d

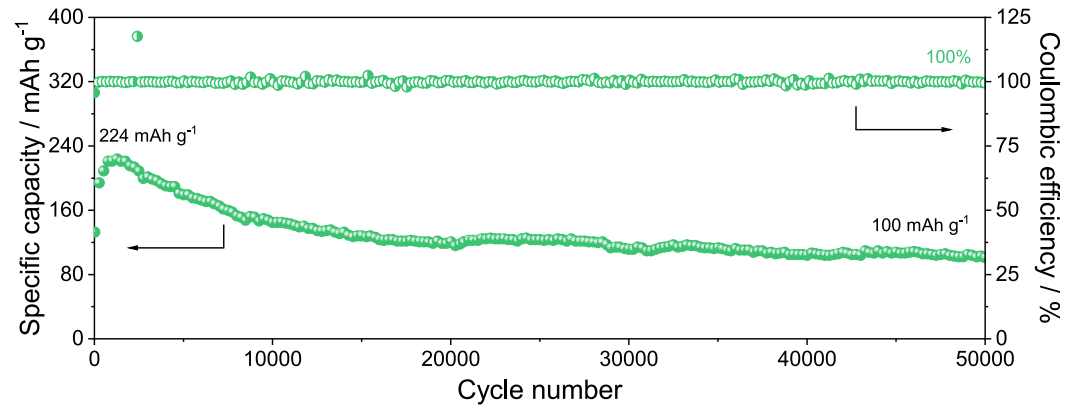

f

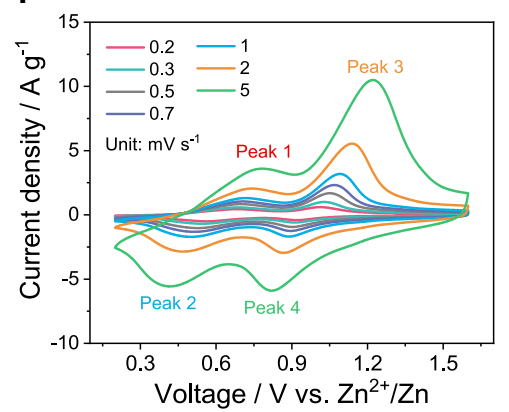

b

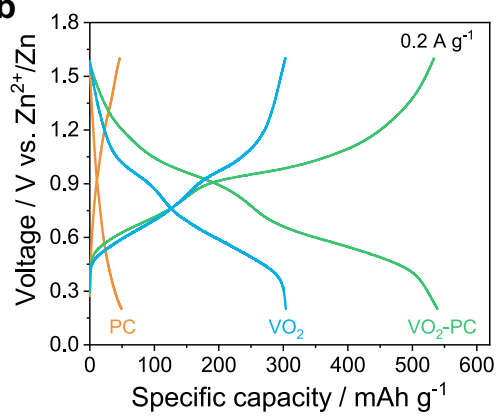

C

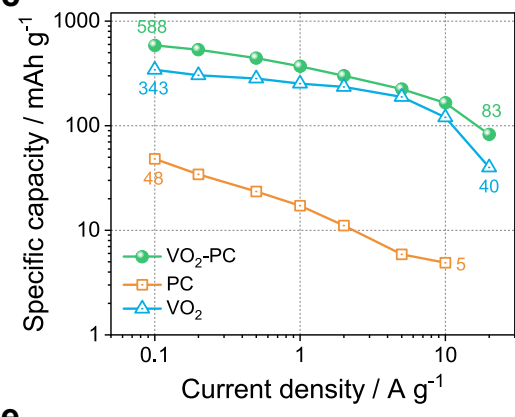

e

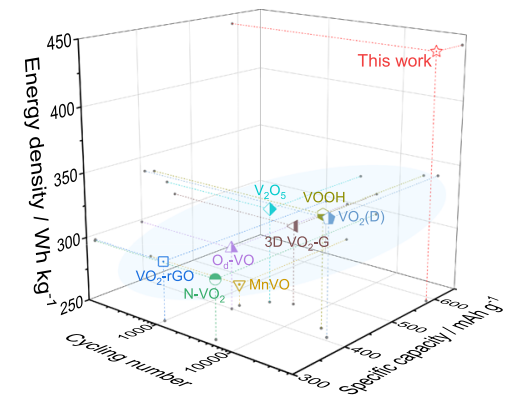

h

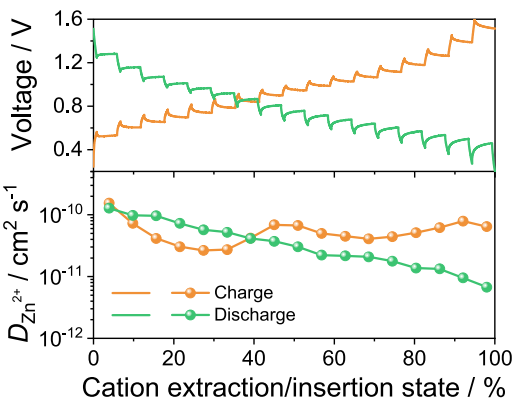

Fig. 4 Electrochemical performance of ZIBs with various electrodes. a CV curves for the initial 3 cycles of $V \mathrm{O}_{2}-\mathrm{PC}$ at $0.2 \mathrm{mV} \mathrm{s}^{-1}$. b GCD curves, $\mathbf{c}$ Ragone plots, and $\mathbf{d}$ cycling stability at $10 \mathrm{Ag}^{-1}$. e Comparison of main electrochemical parameters of the $\mathrm{VO}_{2}-\mathrm{PC}$-based ZIB with other reported devices. $\mathbf{f} \mathrm{CV}$ curves at various scan rates. $\mathbf{g}$ The corresponding log (current) vs. log (scan rate) of each redox peak. $\mathbf{h}$ GITT curves and $\mathrm{Zn}^{2+}$ diffusion coefficient at charging/discharging.

gradient. It is worth mentioning that the gradual voltage growth following the self-discharge process with a temperature of $0 \mathrm{~K}$ can be attributed to the chemically self-charging behaviors ${ }^{15}$.

Energy storage behavior of ZIBs. To evaluate the energy storage ability of as-constructed devices, coin-type ZIBs are reasonably carried out. Figure $4 \mathrm{a}$ profiles the cyclic voltammetry $(\mathrm{CV})$ curves of $\mathrm{VO}_{2}$-PC-based ZIB at a scan rate of $0.2 \mathrm{mV} \mathrm{s}^{-1}$. Clearly, two pairs of redox peaks at around $0.56 / 0.68 \mathrm{~V}$ and $0.92 / 1.01 \mathrm{~V}$ belong to the multiple insertion/extraction procedures of electrolyte ions in $\mathrm{VO}_{2}$ $\left(\mathrm{Zn}_{x} \mathrm{VO}_{2} \cdot y \mathrm{H}_{2} \mathrm{O} \leftrightarrow \mathrm{VO}_{2}+x \mathrm{Zn}^{2+}+y \mathrm{H}_{2} \mathrm{O}+2 x \mathrm{e}^{-}\right)^{27}$. The almost overlapping $\mathrm{CV}$ curves at the initial three cycles further indicate the highly reversible electrochemical behavior. Besides, the $\mathrm{VO}_{2}-\mathrm{PC}$ displays the largest enclosed $\mathrm{CV}$ area among $\mathrm{PC}$ and commercial $\mathrm{VO}_{2}$, suggesting its highest charge storage ability (Supplementary Fig. 8a). The galvanostatic charge/discharge (GCD) curves at a low current density of $0.2 \mathrm{~A} \mathrm{~g}^{-1}$ are in keeping with the same redox reactions of $\mathrm{CV}$ curves (Fig. 4b). As a result, a high discharge capacity of $539 \mathrm{mAh} \mathrm{g}^{-1}$ can be achieved for $\mathrm{VO}_{2}-\mathrm{PC}$ in this case, which is significantly higher than that of $\mathrm{VO}_{2}\left(303.8 \mathrm{mAh} \mathrm{g}^{-1}\right)$ and PC (49.3 $\left.\mathrm{mAh} \mathrm{g}^{-1}\right)$. Meanwhile, the highly reversible behavior and rate capability of $\mathrm{VO}_{2}$-PC are investigated by GCD tests at different current densities from 0.1 to $20 \mathrm{~A} \mathrm{~g}^{-1}$ (Supplementary Fig. 8b).
Compared to the $\mathrm{VO}_{2}$ and $\mathrm{PC}$, the $\mathrm{VO}_{2}-\mathrm{PC}$ exhibits an excellent capacitive performance together with high reversibility at each rate (Fig. 4c). Impressively, the reversible discharging capacity can still retain $80 \mathrm{mAh} \mathrm{g}^{-1}$ even at a high current density of $20 \mathrm{Ag}^{-1}$. When the current density was adjusted back to $0.1 \mathrm{Ag}^{-1}$, the specific capacity can be nearly recovered to $530 \mathrm{mAh} \mathrm{g}^{-1}$, which maintains about $91 \%$ of the initial discharging capacity. The corresponding GCD curves of the $\mathrm{VO}_{2}$-PC-based ZIB at various current densities are plotted in Supplementary Fig. 8c. The obvious electrochemical platforms that appeared in the charging and discharging curves directly confirm the mixed energy storage processes endowed by $\mathrm{V}$-species. Ragone plots show the satisfying rate capability of $\mathrm{VO}_{2}$-PC. As summarized in Supplementary Fig. 8d, both a superior energy density of $442 \mathrm{Wh} \mathrm{kg}^{-1}$ at $112 \mathrm{~W} \mathrm{~kg}^{-1}$ and a high power density of $14.8 \mathrm{~kW} \mathrm{~kg}^{-1}$ at $43 \mathrm{Wh} \mathrm{kg}^{-1}$ can be reached based on the cathode mass, which surpasses those of the other devices with $\mathrm{PC}$ and $\mathrm{VO}_{2}$ as electrode materials. When taking into consideration of the total mass $\left(m_{\mathrm{VO}_{2}-\mathrm{PC}}+m_{\mathrm{Zn}}\right)$, a maximum energy/power density of $33.0 \mathrm{Wh} \mathrm{kg}^{-1} / 1105.4 \mathrm{~W} \mathrm{~kg}^{-1}$ can be retained, implying its satisfactory application as one of the systems for large-scale energy storage (Supplementary Note 3 and Supplementary Table 3). Remarkably, the specific capacity of $\mathrm{VO}_{2}$-PCbased ZIB still can retain approximately $100 \mathrm{mAh} \mathrm{g}^{-1}$ even over 
50,000 cycles at a relatively high current density of $10 \mathrm{Ag}^{-1}$, and the corresponding Coulombic efficiency is about $100 \%$ for each cycle (Fig. 4d). Such results also are dramatically higher than that of $\mathrm{PC}$ - and $\mathrm{VO}_{2}$-based ZIBs (Supplementary Fig. 8e). Compared with the previously reported vanadium-based cathodes for aqueous ZIBs, the $\mathrm{VO}_{2}-\mathrm{PC}$ electrode exhibits outstanding performances in terms of specific capacity, cyclic stability, and energy density (Fig. 4e $)^{28-36}$. These results demonstrate the satisfying ability of this combination of $\mathrm{PC}$ matrix and $\mathrm{VO}_{2}$ crystal in the storage of $\mathrm{Zn}^{2+}$ ion, which suggests that the $\mathrm{VO}_{2}-\mathrm{PC}$ would hold a promising performance to fulfill the requirements of $\mathrm{Zn}$-based systems.

The rate performance of $\mathrm{VO}_{2}-\mathrm{PC}$ is greatly determined by its electrochemical kinetics, which is reasonably studied by $\mathrm{CV}$ measurements from 0.2 to $5 \mathrm{mV} \mathrm{s}^{-1}$ (Fig. 4f). Typically, the surface-induced capacitance and diffusion-controlled procedure can be indexed according to the relationship between peak

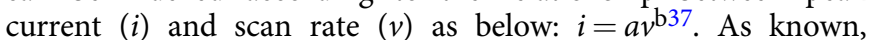
$b=0.5$ indicates that the electrochemical process is totally controlled by diffusion, while $b=1.0$ represents the capacitance-dominated process. Notably, the calculated $b$ values for peaks $1-4$ are $0.65,0.75,0.88$, and 0.83 , respectively (Fig. $4 \mathrm{~g}$ ), which reveals that the electrochemical kinetics of $\mathrm{VO}_{2}-\mathrm{PC}$ is dominated by surface capacitive behavior. Furthermore, the capacity can be detailly divided into capacitance $\left(k_{1} v\right)$ and diffusion-controlled $\left(k_{2} v^{1 / 2}\right)$ contribution by the following formula ${ }^{38}$ :

$$
i=i_{\text {cap }}+i_{\text {diff }}=k_{1} v+k_{2} v^{1 / 2}
$$

As displayed in Supplementary Fig. 8f, a high capacitive contribution of $53 \%$ can be obtained at the scan rate of $0.2 \mathrm{mV} \mathrm{s}^{-1}$. With the increase of scan rate from 0.2 to $5 \mathrm{mV} \mathrm{s}^{-1}$, the capacitive contribution of $\mathrm{VO}_{2}-\mathrm{PC}$ electrode gradually increases from $53 \%$ to $87.5 \%$, indicating fast charge transfer feature as well as good rate capability. In addition, the galvanostatic intermittent titration technique (GITT) was performed to investigate the $\mathrm{Zn}^{2+}$ diffusion behavior in the $\mathrm{VO}_{2}$-PC electrode during charging and discharging processes (Fig. $4 \mathrm{~h})$. The average diffusion coefficient of $\mathrm{Zn}^{2+}\left(D_{\mathrm{Zn}}\right)$ can be calculated as high as $10^{-10.5} \mathrm{~cm}^{2} \mathrm{~s}^{-1}$ for the whole charge and discharge, which suggests the fast transport of $\mathrm{Zn}^{2+}$ in the cathode. Such a high $\mathrm{Zn}^{2+}$ diffusion coefficient can correspond to the continuous PC network and embedded electroactive $\mathrm{VO}_{2}$. It is worth mentioning that the decrease of $D_{\mathrm{Zn}}$ value from about $10^{-10}$ to $10^{-11} \mathrm{~cm}^{2} \mathrm{~s}^{-1}$ in the discharge process can be attributed to the gradual increase of $\mathrm{Zn}^{2+}$ content in the $\mathrm{VO}_{2}-\mathrm{PC}$ electrode, which further indicates the good ability of $\mathrm{VO}_{2}-\mathrm{PC}$ cathode for ions diffusion.

Energy storage mechanism of ZIBs. Inspired by the superior performances of $\mathrm{VO}_{2}-\mathrm{PC}$, various ex-situ measurements were conducted to reveal the detailed reaction mechanism during electrochemical tests. For convenience, the $\mathrm{VO}_{2}-\mathrm{PC}$ electrode at specific voltage used for analysis is marked as state $x$, as shown in Fig. 5a. Before the test, the $\mathrm{VO}_{2}-\mathrm{PC}$-based $\mathrm{ZIB}$ is discharged to $0.2 \mathrm{~V}$ and then charged/discharged to the selected voltage state. From the XRD patterns of the $\mathrm{VO}_{2}$ - $\mathrm{PC}$ cathode at various states (Fig. 5b), the characteristic peaks at $\sim 18^{\circ}$ and $\sim 25^{\circ}$ can be detected in all patterns, which could be assigned to the (100) plane of PTFE (PDF\#54-1595) and the (110) plane of monoclinic $\mathrm{VO}_{2}$ (PDF\#81-2392) ${ }^{39}$. During the charging process from state I to state III, the interlayer space corresponded to (110) plane is gradually reduced because of the slight positive shift of peaks at $\sim 25^{\circ}$, which indicates the extraction of electrolyte ions from the $\mathrm{VO}_{2}$ crystal. Notably, the negative shift of (110) plane during the discharging process further confirms the insertion of electrolyte ions into $\mathrm{VO}_{2}$, suggesting a highly reversible behavior for ions storage. In addition, the byproduct-free $\mathrm{Zn}$ anode is also identified by the corresponding XRD patterns (Fig. 5c), meaning its highly reversible and durable feature. The added peak at $\sim 26.3^{\circ}$ can be well matched with the (002) plane of graphite, suggesting the successful modification of $\mathrm{Zn}$ surface ${ }^{37}$. Moreover, ex-situ XPS analyses were employed to explore the chemical states of the initial and the fully charged/discharged electrodes (Fig. 5d-f). In Fig. $5 \mathrm{~d}$, the high intensity of $\mathrm{Zn} 2 p$ peaks in the state $\mathrm{V}$ clearly demonstrates the insertion of $\mathrm{Zn}^{2+}$ into $\mathrm{VO}_{2}$. The appearance of the $\mathrm{Zn}$ signal at state III is probably caused by the presence of residual zinc salts, indicating that most of $\mathrm{Zn}^{2+}$ can be extracted from the $\mathrm{VO}_{2}-\mathrm{PC}$ cathode ${ }^{18}$. To our knowledge, the GCD processes of $\mathrm{V}$-based ZIBs could be accompanied by the valence change of $\mathrm{V}$ element in $\mathrm{VO}_{2}$ crystals. Compared with the $\mathrm{V}^{4+}$ existing in the initial electrode, the $\mathrm{V} 2 p$ peaks move to low binding energy during discharge together with a high $\mathrm{V}^{3+} / \mathrm{V}^{4+}$ ratio of 2.65 , which suggests the reduction of vanadium-oxide (Fig. 5e). In the charging process, the $\mathrm{V}^{3+} / \mathrm{V}^{4+}$ ratio decreases to 0.50 , and the peaks of $\mathrm{V} 2 p$ are nearly recovered to the initial state due to the oxidization of vanadium. Besides, the content of $\mathrm{H}_{2} \mathrm{O}$ gradually enhances during the discharging state and decreases during the charging state, which directly confirms that the solvation effect can promote the diffusion of $\mathrm{H}_{2} \mathrm{O}$ to $\mathrm{VO}_{2}$ along with the insertion of $\mathrm{Zn}^{2+}$ (Fig. 5f) ${ }^{29}$. The above results propose that the $\mathrm{VO}_{2}$-PC-based ZIBs exhibit a hybrid energy storage mechanism including the ions adsorption on $\mathrm{PC}$ and the redox reaction in $\mathrm{VO}_{2}$.

Performance of wearable ZTCCs. Inspired by the satisfying performance of ZTCCs for energy storage and conversion, we further designed a quasi-solid-state device using polyacrylamide (PAM)-based gel for wearable application (Fig. 6a). Considering that the $\mathrm{Zn}^{2+}$ can be extracted from $\mathrm{Zn}_{x} \mathrm{VO}_{2} \cdot y \mathrm{H}_{2} \mathrm{O}$ on the hot side and deposited on $\mathrm{Zn}$ electrode on the cold side, the $\mathrm{VO}_{2}$ cathode acts as an electrode for energy conversion and storage simultaneously. In such wearable ZTCCs, the $\mathrm{Zn}^{2+}$ can diffuse to $\mathrm{VO}_{2}$ firstly and react into $\mathrm{Zn}_{x} \mathrm{VO}_{2} \cdot y \mathrm{H}_{2} \mathrm{O}$ after a fully discharged procedure. As profiled in Fig. 6b, the ZTCC can charge and discharge under multiple modes. When the ZTCC is thermally charged with the temperature difference between skin temperature $\left(T_{\text {skin }}\right)$ and ambient temperature $\left(T_{\text {ambient }}\right)$, the output voltage can slowly reach to $\sim 0.6 \mathrm{~V}$ (Fig. $6 \mathrm{~b}$ ). It is worth mentioning that almost $1.3 \mathrm{~V}$ can be achieved with two ZTCCs in series $(\Delta T$ of $\sim 12 \mathrm{~K}$ ). Such integrated devices can be further galvanostatically charged from thermal charge state $(\sim 1.3 \mathrm{~V})$ to fully charged state $(3.2 \mathrm{~V})$. To demonstrate the practical application of wearable ZTCCs in real conditions via a facile way, only two pouch ZTCCs connected in series were employed to power a smartwatch (Fig. 6c-e), which is much easier than that of practical e-TE or i-TE integration. Moreover, as-constructed ZTCCs can work normally even under harsh conditions (Fig. 6e), confirming the availability and durability of developed ZTCCs.

\section{Discussion}

In summary, we have demonstrated the design and construction of ZTCCs with $\mathrm{Zn}$ anode and $\mathrm{VO}_{2}$ - $\mathrm{PC}$ cathode, which is prepared by a universal solution-based strategy, for highperformance low-grade heat conversion and $\mathrm{Zn}^{2+}$ storage. It is worth mentioning that the evenly distributed $\mathrm{VO}_{2}$ in the PC provides abundant electroactive sites, delivering high capability and fast kinetics for $\mathrm{Zn}^{2+}$ storage. The carbon matrix acts as continuous pathways for charge transport and channels for electrolyte ions diffusion. Consequently, a high thermopower of $12.5 \mathrm{mV} \mathrm{K}^{-1}$ can be achieved by $\mathrm{VO}_{2}-\mathrm{PC}$, which is beneficial to the synergistic effect of the thermogalvanic effect and 


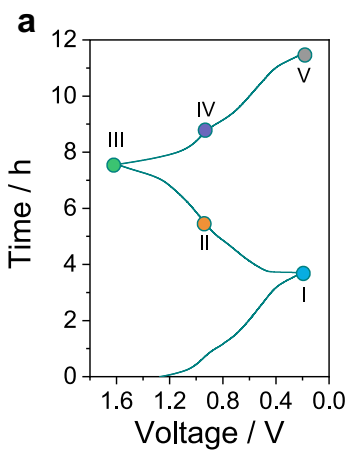

d

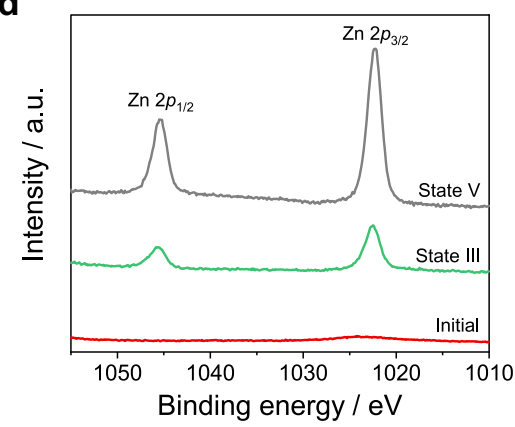

b

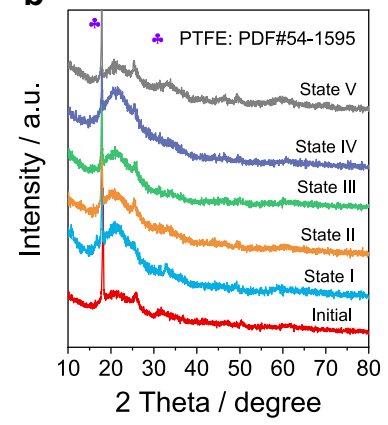

e

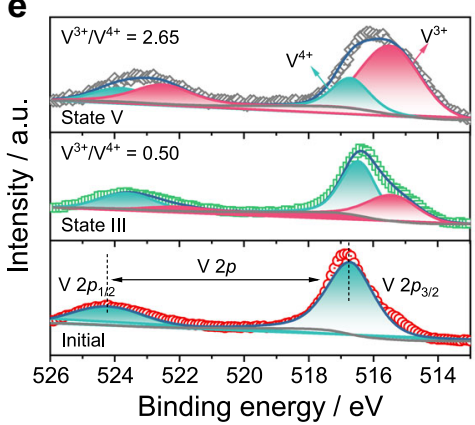

c
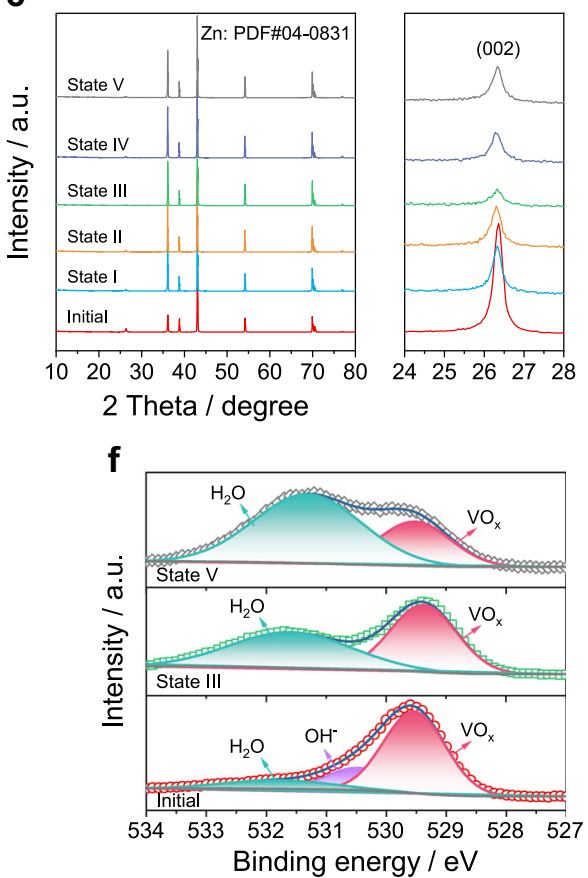

Fig. 5 The mechanism of $\mathbf{V O}_{\mathbf{2}}$-PC-based ZIBs. a The GCD curves at $0.1 \mathrm{Ag}^{-1}$. $\mathbf{b}, \mathbf{c}$ The corresponding ex-situ XRD patterns of $\mathbf{b} \vee \mathrm{O}_{2}-\mathrm{PC}$ cathode and $\mathbf{c} \mathrm{Zn}$ $\mathrm{G}$ anode. $\mathbf{d}-\mathbf{f}$ The corresponding ex situ XPS spectra of $\mathbf{d} \mathrm{Zn} 2 p$, e $\vee 2 p$, and $\mathbf{f} \mathrm{O} 1 \mathrm{~s}$.
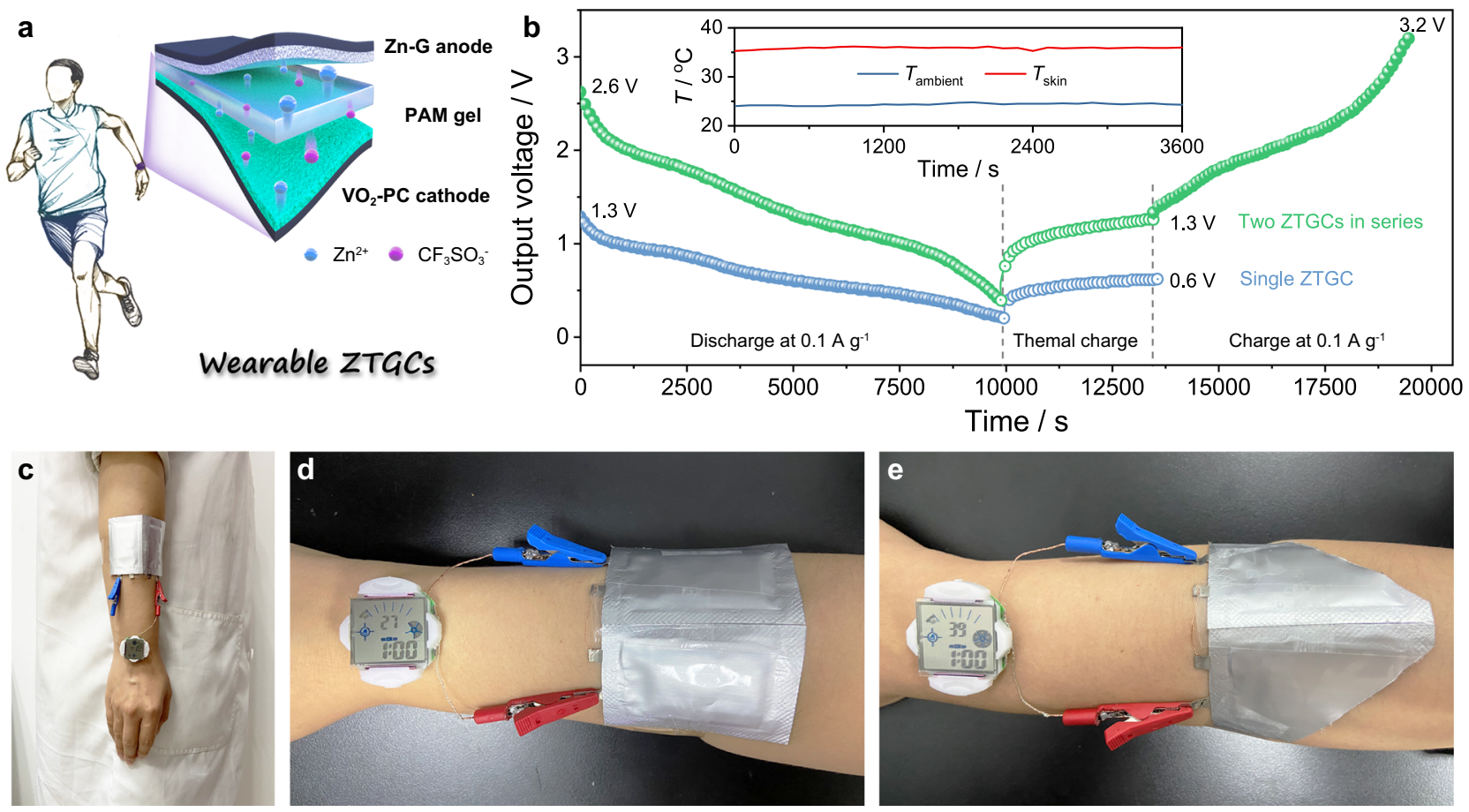

Fig. 6 Proof of concept of ZTCCs at various modes. a Schematic drawing of the wearable ZTCCs. b Charge/discharge process at galvanostatic and/or thermal models. The inset shows the change of body heat and ambient temperature. c-e A smartwatch powered by two ZTCCs in series at $\mathbf{c}$, $\mathbf{d}$ initial state and $\mathbf{e}$ the harsh condition.

thermodiffusion. As a proof-of-concept, ZTCCs exhibits a high output voltage of $\sim 1 \mathrm{~V}$ and a record-breaking output power of $1220 \mu \mathrm{W}$ as well as high Carnot-relative efficiency of $7.25 \%$ under the temperature difference of $45 \mathrm{~K}$. Moreover, the $\mathrm{VO}_{2^{-}}$ $\mathrm{PC}$ exhibits an excellent $\mathrm{Zn}$-ion storage behavior, such as a high specific capacity $\left(588 \mathrm{mAhg}^{-1}\right.$ at $\left.0.1 \mathrm{Ag}^{-1}\right)$, good rate capability $\left(80 \mathrm{mAh} \mathrm{g}^{-1}\right.$ even at $\left.20 \mathrm{Ag}^{-1}\right)$, and impressive cycling stability over 50,000 cycles. Moreover, two wearable ZTCCs connected in series demonstrate high availability and durability in the electronics area. All the findings have confirmed that the proposed ZTCC would be a potential candidate for promising energy conversion and storage, and the detailed studies of involved mechanisms may provide deep insight for the development of zinc-based devices. 


\section{Methods}

Preparation of $\mathbf{V O}_{2}-\mathbf{P C}$. Typically, $1.0 \mathrm{~g}$ of ammonium metavanadate and $0.25 \mathrm{~g}$ dopamine hydrochloride were dissolved in $100 \mathrm{~mL}$ deionized water. Then, $200 \mathrm{~mL}$ of ethanol was added to the above solution with stirring for about $10 \mathrm{~min}$. After that, $1.5 \mathrm{~mL}$ of $\mathrm{NH}_{3} \cdot \mathrm{H}_{2} \mathrm{O}$ was dropped into it and stirred for another $2 \mathrm{~h}$ to obtain $\mathrm{V}$-PDA precursors. Finally, the $\mathrm{VO}_{2}-\mathrm{PC}$ was prepared by the pyrolysis of $\mathrm{V}$-PDA at $500{ }^{\circ} \mathrm{C}$ for $3 \mathrm{~h}$ with a heating rate of $3{ }^{\circ} \mathrm{C} \mathrm{min}^{-1}$ under argon flow. In addition, the $\mathrm{Mo}_{4} \mathrm{O}_{8}-\mathrm{PC}$ and $\mathrm{W}_{3} \mathrm{O}_{9}-\mathrm{PC}$ were synthesized by the same strategy as above, only changing the added metal source to ammonium molybdate tetrahydrate and ammonium metatungstate.

Electrochemical measurements. All the electrochemical performances for the conversion of low-grade heat to electricity were evaluated on a standard electrochemical workstation (CHI 660C) with a non-isothermal $\mathrm{H}$ cell using $0.5 \mathrm{~mol} \mathrm{~L}^{-1}$ $\mathrm{Zn}\left(\mathrm{CF}_{3} \mathrm{SO}_{3}\right)_{2}$. Typically, the working electrode was prepared by the coating of asobtained samples onto graphite paper together with acetylene and polyvinylidene fluoride according to a mass ratio of 7:2:1. It is worth mentioning that the mass loading in the working electrode was about $1.2 \mathrm{mg} \mathrm{cm}^{-2}$. Besides, the $\mathrm{Zn}$ anode used was modified by graphite following pencil drawing ${ }^{37}$. For ZIB tests, the CV curves and GITT were performed by the Biologic VMP-300 workstation. The GCD measurements and cycling stability were collected on the CT3001A Land Battery Test System. Notably, the specific capacity and energy density of ZIBs were recorded directly from Land Battery Test System.

The quasi-solid-state ZTCCs were constructed by sandwiching the Zn-G anode, gel electrolyte, and $\mathrm{VO}_{2}$-PC cathode. The gel electrolyte was prepared through polymerization of acrylamide (AM) and subsequent electrolyte immersion. Briefly, $2.5 \mathrm{~g}$ of AM, $1.5 \mathrm{mg}$ of $N, N^{\prime}$-methylenebisacrylamide, and $10 \mu \mathrm{L}$ of $N, N, N^{\prime}$, $N^{\prime}$-tetramethylethylenediamine were added into $10 \mathrm{~mL}$ of deionized water part by part with vigorous stirring at $\sim 0{ }^{\circ} \mathrm{C}$. After that, $0.25 \mathrm{~g}$ of potassium persulfate was dispersed into the above solution. When polymerizing with an ultraviolet lamp $(60 \mathrm{~W})$ for about $20 \mathrm{~min}$, a transparent hydrogel was prepared. Finally, such hydrogel was immersed in an electrolyte solution to fabricate a flexible $\mathrm{Zn}\left(\mathrm{CF}_{3} \mathrm{SO}_{3}\right)_{2}$-PAM gel electrolyte.

Material characterizations. SEM and TEM were employed on Hitachi S-4800 and JEOL JEM-2100, respectively. Powder XRD was obtained by a PANalytical Empyrean diffractometer with $\mathrm{Cu}$ Ka radiation $(\lambda=1.5406 \AA)$. XPS was carried out by the KRATOS AXIS SUPRA instrument. Raman spectroscopy was conducted by the Horiba Scientific LabRAM HR.

\section{Data availability}

All relevant data that support the findings of this study are presented in the manuscript and supplementary information file. Source data are available from the corresponding author upon reasonable request.

Received: 10 July 2021; Accepted: 9 December 2021; Published online: 10 January 2022

\section{References}

1. He, J. \& Tritt, T. M. Advances in thermoelectric materials research: looking back and moving forward. Science 357, eaak9997 (2017).

2. Han, C. G. et al. Giant thermopower of ionic gelatin near room temperature. Science 368, 1091-1098 (2020).

3. Wang, H. \& Yu, C. Organic thermoelectrics: materials preparation, performance optimization, and device integration. Joule 3, 53-80 (2019).

4. Tan, G., Zhao, L.-D. \& Kanatzidis, M. G. Rationally designing highperformance bulk thermoelectric materials. Chem. Rev. 116, 12123-12149 (2016).

5. Wang, X. et al. Direct thermal charging cell for converting low-grade heat to electricity. Nat. Commun. 10, 4151 (2019).

6. Chen, D. et al. Influence of electrolyte ions on rechargeable supercapacitor for high value-added conversion of low-grade waste heat. J. Power Sources 465, 228263 (2020).

7. Kim, B., Hwang, J. U. \& Kim, E. Chloride transport in conductive polymer films for an n-type thermoelectric platform. Energy Environ. Sci. 13, 859-867 (2020).

8. Yang, P. et al. Wearable thermocells based on gel electrolytes for the utilization of body heat. Angew. Chem. Int. Ed. 55, 12050-12053 (2016).

9. Yu, B. et al. Thermosensitive crystallization-boosted liquid thermocells for low-grade heat harvesting. Science 370, 342-346 (2020).

10. Poletayev, A. D., McKay, I. S., Chueh, W. C. \& Majumdar, A. Continuous electrochemical heat engines. Energy Environ. Sci. 11, 2964-2971 (2018).

11. Blanc, L. E., Kundu, D. \& Nazar, L. F. Scientific challenges for the implementation of Zn-ion batteries. Joule 4, 771-799 (2020).
12. Zhang, N. et al. Materials chemistry for rechargeable zinc-ion batteries. Chem Soc. Rev. 49, 4203-4219 (2020).

13. Jia, X., Liu, C., Neale, Z. G., Yang, J. \& Cao, G. Active materials for aqueous zinc ion batteries: synthesis, crystal structure, morphology, and electrochemistry. Chem. Rev. 120, 7795-7866 (2020).

14. $\mathrm{Li}, \mathrm{Z}$. et al. Progress on zinc ion hybrid supercapacitors: Insights and challenges. Energy Storage Mater. 31, 252-266 (2020)

15. Zhang, Y. et al. A chemically self-charging aqueous zinc-ion battery. Nat. Commun. 11, 2199 (2020)

16. $\mathrm{Li}, \mathrm{Z}$. et al. Impacts of oxygen vacancies on zinc ion intercalation in $\mathrm{VO}_{2}$. ACS Nano 14, 5581-5589 (2020).

17. Li, R. \& Liu, C.-Y. $\mathrm{VO}_{2}$ (B) nanospheres: hydrothermal synthesis and electrochemical properties. Mater. Res. Bull. 45, 688-692 (2010).

18. Chen, L. et al. Ultrastable and high-performance $\mathrm{Zn} / \mathrm{VO}_{2}$ battery based on a reversible single-phase reaction. Chem. Mater. 31, 699-706 (2019).

19. Luo, H. et al. Synergistic deficiency and heterojunction engineering boosted $\mathrm{VO} 2$ redox kinetics for aqueous zinc-ion batteries with superior comprehensive performance. Energy Storage Mater. 33, 390-398 (2020).

20. Wang, H. et al. Underpotential lithium plating on graphite anodes caused by temperature heterogeneity. Proc. Natl Acad. Sci. USA 117, 29453-29461 (2020).

21. Meng, T., Xuan, Y. \& Zhang, X. A thermally chargeable hybrid supercapacitor with high power density for directly converting heat to electricity. ACS Appl. Energy Mater. 4, 6055-6061 (2021).

22. Im, H. et al. High-efficiency electrochemical thermal energy harvester using carbon nanotube aerogel sheet electrodes. Nat. Commun. 7, 10600 (2016).

23. Oh, J. Y. et al. Chemically exfoliated transition metal dichalcogenide nanosheet-based wearable thermoelectric generators. Energy Environ. Sci. 9, 1696-1705 (2016)

24. Kim, C. S. et al. Structural design of a flexible thermoelectric power generator for wearable applications. Appl. Energy 214, 131-138 (2018).

25. $\mathrm{Hu}, \mathrm{R}$. et al. Harvesting waste thermal energy using a carbon-nanotube-based thermo-electrochemical cell. Nano Lett. 10, 838-846 (2010).

26. Duan, J. et al. Aqueous thermogalvanic cells with a high Seebeck coefficient for low-grade heat harvest. Nat. Commun. 9, 5146 (2018).

27. Ding, J. et al. Ultrafast $\mathrm{Zn} 2+$ intercalation and deintercalation in vanadium dioxide. Adv. Mater. 30, 1800762 (2018).

28. Ding, J. et al. Unlocking the potential of disordered rocksalts for aqueous zincion batteries. Adv. Mater. 31, 1904369 (2019).

29. Chen, L., Yang, Z. \& Huang, Y. Monoclinic VO2(D) hollow nanospheres with super-long cycle life for aqueous zinc ion batteries. Nanoscale 11, 13032-13039 (2019).

30. Zhao, J. et al. High-performance flexible quasi-solid-state zinc-ion batteries with layer-expanded vanadium oxide cathode and zinc/stainless steel mesh composite anode. Nano Energy 62, 94-102 (2019).

31. Liu, Y.-Y. et al. Nsutite-type VO2 microcrystals as highly durable cathode materials for aqueous zinc-ion batteries. Chem. Eng. J. 417, 128408 (2021)

32. Deka Boruah, B. et al. Vanadium dioxide cathodes for high-rate photorechargeable zinc-ion batteries. Adv. Energy Mater. 11, 2100115 (2021).

33. Luo, H. et al. Synergistic nanostructure and heterointerface design propelled ultra-efficient in-situ self-transformation of zinc-ion battery cathodes with favorable kinetics. Nano Energy 81, 105601 (2021)

34. Wang, L., Huang, K.-W., Chen, J. \& Zheng, J. Ultralong cycle stability of aqueous zinc-ion batteries with zinc vanadium oxide cathodes. Sci. Adv. 5 eaax4279 (2019)

35. Liu, C. et al. Expanded hydrated vanadate for high-performance aqueous zincion batteries. Energy Environ. Sci. 12, 2273-2285 (2019).

36. Liao, M. et al. A deep-cycle aqueous zinc-ion battery containingan oxygendeficient vanadium oxide cathode. Angew. Chem. Int. Ed. 132, 2293-2298 (2020).

37. Li, Z. et al. Pencil drawing stable interface for reversible and durable aqueous zinc-ion batteries. Adv. Funct. Mater. 31, 2006495 (2020).

38. Li, Z. et al. Flexible and anti-freezing quasi-solid-state zinc ion hybrid supercapacitors based on pencil shavings derived porous carbon. Energy Storage Mater. 28, 307-314 (2020).

39. Huang, J. et al. Polyaniline-intercalated manganese dioxide nanolayers as a high-performance cathode material for an aqueous zinc-ion battery. Nat. Commun. 9, 1-8 (2018)

\section{Acknowledgements}

This work was supported by the Leading Edge Technology of Jiangsu Province (BK20202008-Y. Xuan), National Natural Science Foundation of China (U1802256X.Z., 21773118-X.Z., 21875107-H.D.), Key Research and Development Program in Jiangsu Province (BE2018122-X.Z.), Postgraduate Research \& Practice Innovation Program of Jiangsu Province (KYCX21_0204-Z.L.), and Priority Academic Program Development of Jiangsu Higher Education Institutions (PAPD). 


\section{Author contributions}

Z.L. carried out the experiment. Z.L., Y. Xu, and Y.A. designed and evaluated the electrochemical performances. L.W. analyzed the structural characterization and electrochemical results. Z.L., Y.S., and T.M. organized the figures. H.D., Y. Xuan, and X.Z. supervised the whole work. All authors co-discussed the results and wrote the manuscript.

\section{Competing interests}

The authors declare no competing interests.

\section{Additional information}

Supplementary information The online version contains supplementary material available at https://doi.org/10.1038/s41467-021-27755-x.

Correspondence and requests for materials should be addressed to Yimin Xuan or Xiaogang Zhang.

Peer review information Nature Communications thanks the anonymous reviewers for their contribution to the peer review of this work.
Reprints and permission information is available at http://www.nature.com/reprints

Publisher's note Springer Nature remains neutral with regard to jurisdictional claims in published maps and institutional affiliations.

(c) (i) Open Access This article is licensed under a Creative Commons Attribution 4.0 International License, which permits use, sharing, adaptation, distribution and reproduction in any medium or format, as long as you give appropriate credit to the original author(s) and the source, provide a link to the Creative Commons license, and indicate if changes were made. The images or other third party material in this article are included in the article's Creative Commons license, unless indicated otherwise in a credit line to the material. If material is not included in the article's Creative Commons license and your intended use is not permitted by statutory regulation or exceeds the permitted use, you will need to obtain permission directly from the copyright holder. To view a copy of this license, visit http://creativecommons.org/ licenses/by/4.0/.

(C) The Author(s) 2022 